\title{
TTF1-induced apoptosis of HepG-2 cells through a mitochondrial pathway
}

\author{
YAN LI, LEI BIAN, FENGDE CUI, LIANGCHANG LI and XUEWU ZHANG \\ Basic Medical College, Yanbian University, Yanji, Jilin 133000, P.R. China
}

Received March 9, 2011; Accepted April 13, 2011

DOI: 10.3892/or.2011.1330

\begin{abstract}
The Chinese medicinal herb Sorbaria sorbifolia, native to Changbai Mountain, can induce apoptosis in HepG-2 cells. We studied the mechanism by which 5,2',4'-trihydroxy-6,7, 5 '-trimethoxyflavone (TTF1) isolated from acetic ether extracts of Sorbaria sorbifolia induces apoptosis in HepG-2 cells. The results showed that TTF1 both inhibited cell growth and induced apoptosis. RT-PCR and Western blot analysis showed that TTF1 treatment led to decreased transcription and protein expression of $b c l-2$ and an increase in bax, Cyt-c, caspase-3 and caspase-9. These results together suggest that TTF1 may induce apoptosis of HepG-2 cells through a mitochondrial pathway.
\end{abstract}

\section{Introduction}

Mitochondria are the most important cellular organelles, and changes in their function are closely associated with cell apoptosis. Many factors can induce mitochondrial injury and apoptosis, including signaling through receptors, release of pro-apoptosis factors, over-production of reactive oxygen species, obstacles to energy production and calcium imbalance in the cytosol. Studies have shown that certain gene products related to apoptosis located in mitochondria can lead to enlargement of the mitochondrial membrane and the release of many proteins, such as Cyt-c, Smac/DIBLO, AIF and Omi/ HtrA2. The BCL-2 protein family plays an important role in the regulation of apoptosis. Anti-apoptosis and pro-apoptosis proteins can induce the release of $\mathrm{Cyt}-\mathrm{c}$ by changing the permeability of the mitochondrial membrane. An apoptosome complex then forms through the binding of Cyt-c and Apaf-1 (apoptotic protease activating factor 1), Pro-caspase-9, and dATP. The apoptosome complex dimer then activates caspase-9 and further activates caspase-3, which may next degrade centrosome DNA by DNase activity to induce apoptosis (1-3). Finding a component in Chinese herbal medicine which can

Correspondence to: Dr Xuewu Zhang, Basic Medical College, Yanbian University, Yanji, Jilin 133000, P.R. China

E-mail: zhangxuewu@ybu.edu.cn

Key words: Sorbaria sorbifolia, 5,2', 4'-trihydroxy-6,7, 5'-trimethoxyflavone, apoptosis effectively induce apoptosis is an important area in anti-tumor research within Chinese medicine (4-6). Sorbaria sorbifolia (SS) is rosaceous plant which grows extensively in Changbai Mountain in Yunnan, Guizhou, Sichuan, Hubei, Gansu and Ningxia Provinces. It is used to help with activating blood, dissolving stasis, reducing swelling and easing pain, and healing fractures and injuries from falls. We previously reported that the acetic ether extracts of SS inhibited the growth of HepG-2 cells (7) and mouse S180 sarcoma and downregulated the levels of TNF- $\alpha$, IL-2 and the cellular activity of NK cells (8). In addition, it inhibited the formation of a positive focus in precancerous rat hepatoma GST-P and down-regulated the expression of $p 53$ and $\mathrm{Bcl}-2$. It increased the activity of SOD and GSH-Px and decreased NOS activity and MDA and NO content $(9,10)$. The following six chemicals were identified in the SS extracts: 5,2',4'-trihydroxy-6,7, 5'-trimethoxyflavone (TTF1), 5,7-dihydroxy-8-methoxyflavone, rutin, quercetin, daucosterol, benzoate and p-hydroxybenzoic acid. TTF1 was the first monomeric compound identified from SS (11). Through electron-microscope scanning, transmission electron-microscopy and DNA eletrophoresis, we observed that the acetic ether extracts of SS-induced apoptosis in HepG-2 cells. The primary component effecting apoptosis was TTF-1, but its mechanism is still not known. This study focuses on the mechanism of TTF1-induced apoptosis of HepG-2 cells through a mitochondrial pathway.

\section{Materials and methods}

Extraction of TTF1. TTF1 was separated using the water extraction and alcohol precipitation (WAE) method on $10 \mathrm{~kg}$ SS (collected from Jilin Province) as previously described (8).

Cell culture. The HepG-2 cell line was purchased from KeyGEN Co., Ltd. (Nanjing, China). Cells were grown in RPMI-1640 supplemented with $10 \%$ FBS, $100 \mathrm{U} / \mathrm{ml}$ penicillin, and $100 \mathrm{mg} / 1$ streptomycin. Cells were cultured at $37^{\circ} \mathrm{C}$ in a humidified incubator containing $5 \% \mathrm{CO}_{2}$. Cells in the logarithmic growth phase were used for tests.

MTT assay of the cell growth inhibition rate. Cells were seeded in a 96-pore plate at an initial concentration of $1 \times 10^{6} / 1$. Cells were treated with different concentration of TTF1 (25, $50,100,200$, or $400 \mu \mathrm{mol} / \mathrm{l}$ ) with five replicates for each concentration. The positive control contained $5 \mu \mathrm{mol} / \mathrm{l}$ adriamycin 
(ADR, Wanle Pharmaceutics, Shenzhen, China), and a negative control was also included. After culturing for 24,48 or $72 \mathrm{~h}$, $20 \mu \mathrm{l}$ of $5 \mathrm{~g} / \mathrm{l}$ MTT was added to each well and culturing continued for $4 \mathrm{~h}$. The supernatant of each well was removed and $150 \mu 1$ of DMSO was added. After shaking the plate for $15 \mathrm{~min}$, the optical density of wells was measured at a wavelength of $490 \mathrm{~nm}$ with a microplate reader (Bio-Rad, USA). The inhibition rate was calculated as follows: IR $(\%)=$ (1-optical density of the control sample/optical density of the experimental sample) $\mathrm{x} 100 \%$. The $\mathrm{IC}_{50}$ was also calculated.

Flow cytometry (FCM) apoptosis analysis. HepG-2 cells were seeded at an initial concentration of $1 \times 10^{6} / 1$ in a 6 -well plate. After culturing for $24 \mathrm{~h}$, cells were treated with 50 or $100 \mu \mathrm{mol} / 1 \mathrm{TTF} 1$. ADR $(5 \mu \mathrm{mol} / \mathrm{l})$ was used as a positive control, and a negative control was also included. Cells were collected after $48 \mathrm{~h}$ by centrifuging at $1000 \mathrm{x} \mathrm{g}$ for $5 \mathrm{~min}$ and washed twice with phosphate-buffered saline (PBS). Cells were suspended with $200 \mu \mathrm{l}$ binding buffer, and then $10 \mu \mathrm{l}$ Annexin V-FITC, and $5 \mu \mathrm{l}$ protein inhibitor (PI) were added before incubation in the dark for $30 \mathrm{~min}$. Binding buffer $(300 \mu \mathrm{l})$ was then added, and apoptosis was analyzed using FCM (model, FACSCalibur, USA) and ModfitLT3.0 software.

ELISA for DNA assessment during apoptosis. Cells were cultured for $48 \mathrm{~h}$. The OD value of DNA fragments was assayed using an apoptosis testing kit (Roche, USA). The results were calculated as the OD value of the experimental sample/the OD value of the control.

Observation of apoptosis using transmission electron microscopy. Cells were cultured for $48 \mathrm{~h}$ and centrifuged at $1000 \mathrm{x} \mathrm{g}$ for $5 \mathrm{~min}$. The cell pellet was collected and fixed with $4 \mathrm{mg} / 1$ glutaraldehyde for $2 \mathrm{~h}$ and then treated with $1 \mathrm{mg} / \mathrm{l}$ osmic acid for $30 \mathrm{~min}$. Cells were dehydrated gradually with ethanol and covered with epoxy resin. The cells were sliced to a thickness of $50 \mathrm{~nm}$. After staining with uranyl acetate and lead citrate, apoptosis was observed using a transmission electron microscope.

Immunohistochemistry for bcl-2 and bax. Cells were cultured for $48 \mathrm{~h}$ and the expression levels of bcl-2 and bax were analyzed by immunohistochemistry using mouse anti-human bcl-2 and bax antibodies (Boshide Biotechnology Company, Wuhan, China). The highest density of positive cells was analyzed with photography of the physical cells in true colors. Five statistical fields were chosen for each treatment condition, and the mean was calculated as the positive expression rate of genes related to apoptosis.

RT-PCR for mRNA analysis of bcl-2, bax, Cyt-c, caspase-3 and caspase-9. After culture for $48 \mathrm{~h}$, total cellular RNA was extracted using TRIzol reagent (KeyGEN Co., Ltd.) and the first strand of cDNA was synthesized. The primers for PCR used were as follows: bcl-2 sense primer: 5'-GTGGAGGA GCTCTTCAGGGA-3', anti-sense primer: 5'-AGGCACCC AGGGTGATGCAA-3', product: $304 \mathrm{bp}$; bax sense primer: 5'-GGCCCACCAGCTCTGAGCAGA-3', anti-sense primer: 5'-GCCACGTGGGCGTCCCAAAGT-3', product: 477 bp; Cyt-c sense primer: 5'-TGAAGCCGCTCGCAAGACTCC-3',

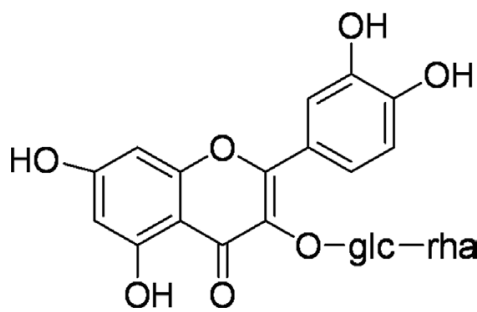

Figure 1. Chemical structure of TTF1.
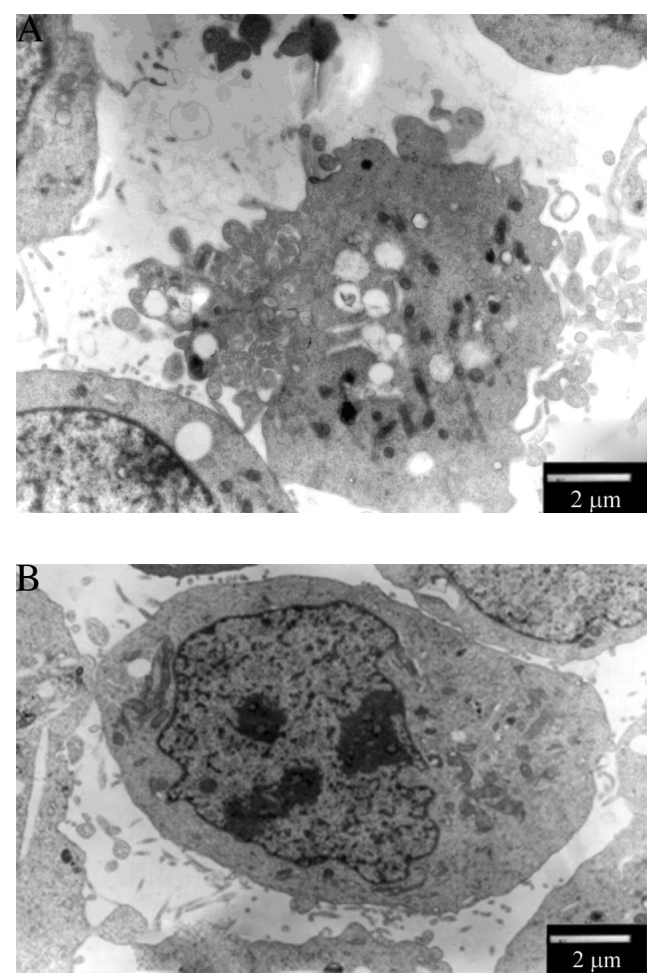

Figure 2. Observation of apoptosis using a transmission electron microscope (x4,000 magnification). After treatment with TTF1, cells were shrunken and cytosol was condensed. The nuclear chromosome formed a crescent in the nuclear membrane and nuclear fragments were observed. (A) HepG-2 cells were treated with $100 \mu \mathrm{mol} / 1 \mathrm{TTF} 1$. (B) Control group cells were treated with normal saline using the same total volume as TTF1 treatment.

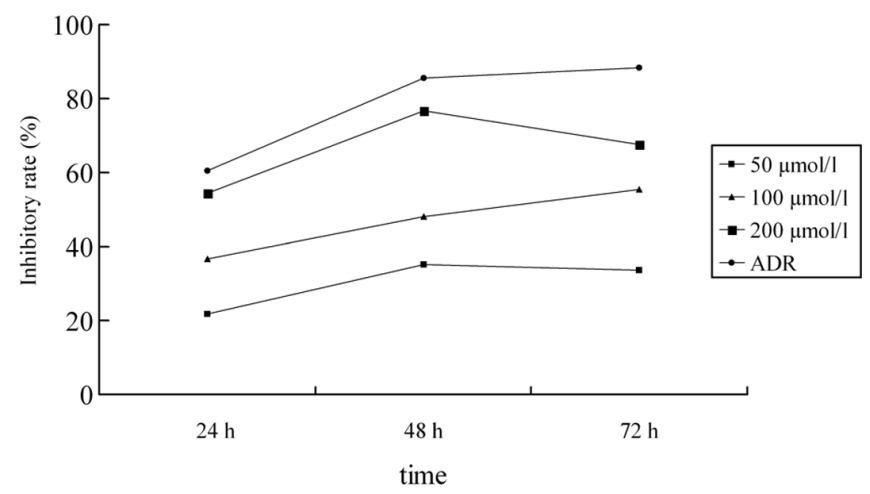

Figure 3. Inhibitory effect of TTF1 on HepG-2 cells detected by MTT assay. HepG-2 cells were treated with different concentrations of TTF1 $(50,100$, $200 \mu \mathrm{mol} /)$, ADR $(5 \mu \mathrm{mol} / \mathrm{l})$ and Con (control group cells were treated with normal saline using the same volume as TTF1 treatment) at three time points $(24,48$ and $72 \mathrm{~h})$. The MTT assay and the cell inhibitory rate were analyzed. 
A

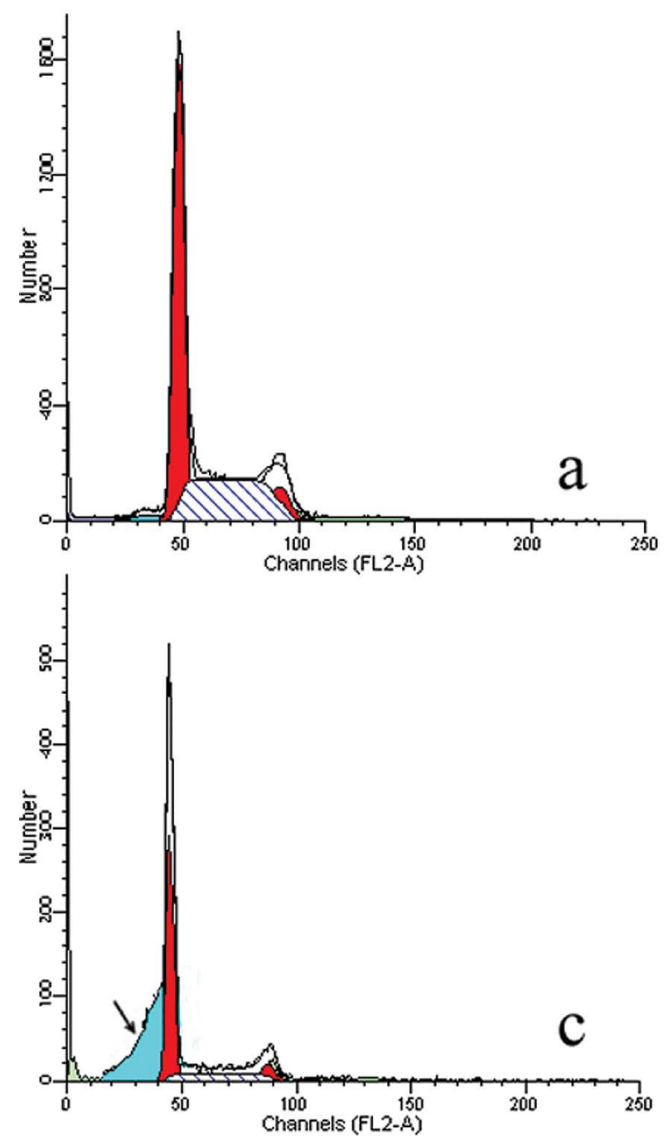

B

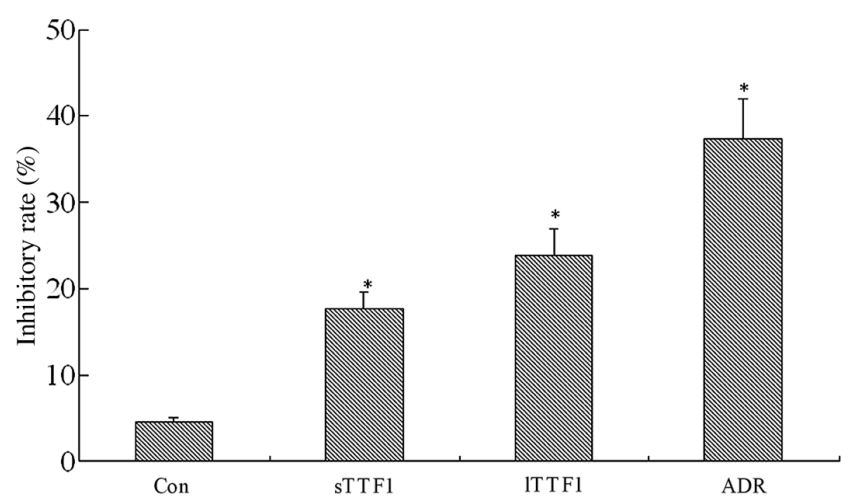

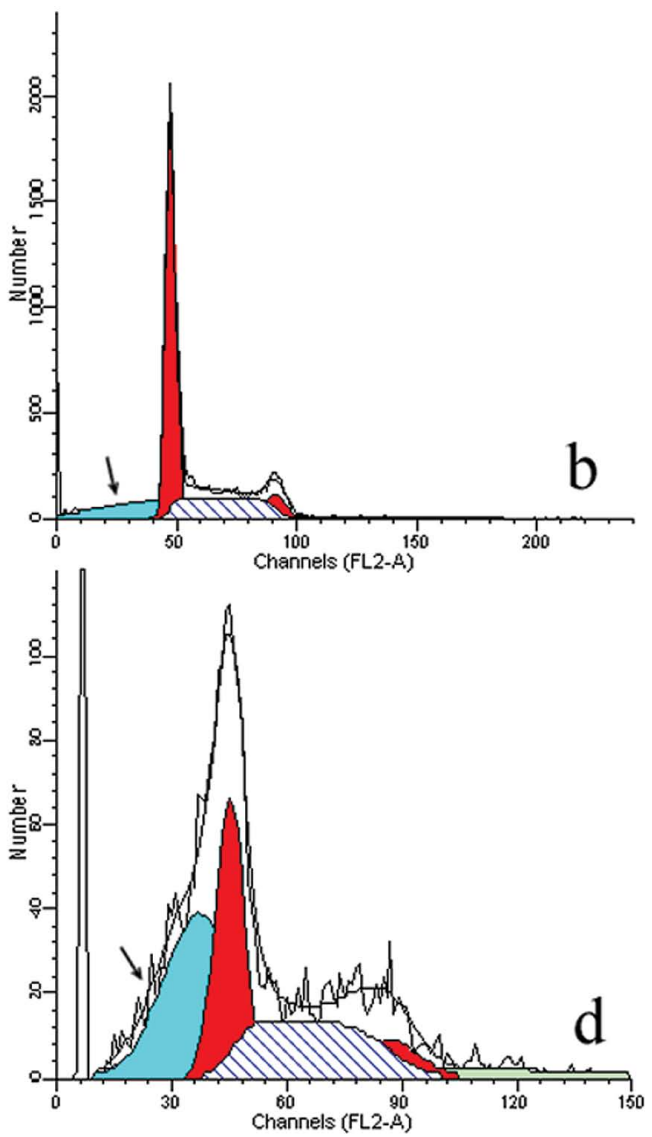

$\mathrm{C}$

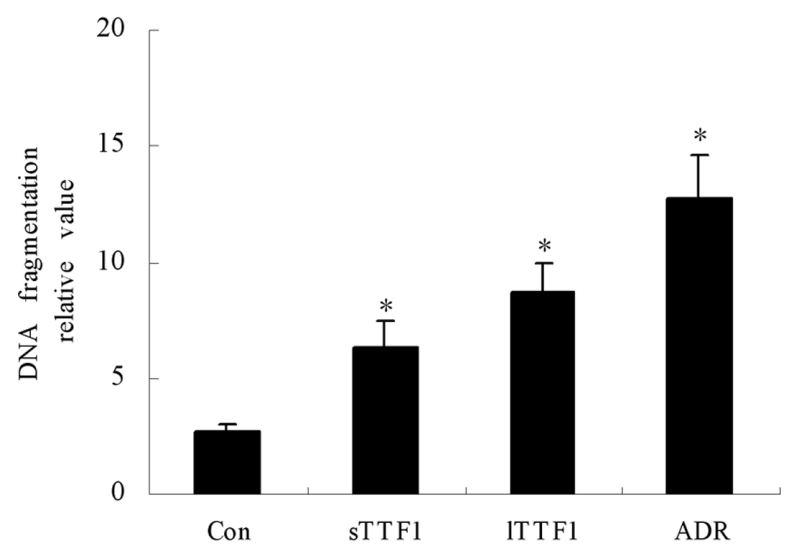

Figure 4. Apoptosis of HepG-2 cells detected by flow cytometry (FCM) and ELISA. HepG-2 cells were treated with different concentrations of TTF1 (b, sTTF1: $50 \mu \mathrm{mol} / 1$; c, ITTF1: $100 \mu \mathrm{mol} / 1)$; d, ADR (5 $\mu \mathrm{mol} / 1)$; and a, Con (control group cells were treated with normal saline using the same volume as TTF1 treatment) at $48 \mathrm{~h}$. Cells in each group were analyzed by flow cytometry (A) and ELISA (C). The apoptotic peak observed in FCM analysis is shown with arrows (A). Cell inhibitory rates were quantified as B. (C) DNA fragmentation was measured by ELISA. "P $<0.05$ vs Con.

anti-sense primer: 5'-GGCTGTCAAAAGGGGCGGTCT-3', product: $204 \mathrm{bp}$; caspase-9 sense primer: 5'- GCTTAGGGT CGCTAATGCTG-3', anti-sense primer: 5'-TGTCGTCAATC TGGAAGCTG-3', product: 273 bp; caspase-3 sense primer: 5'-ATGGAAGCGAATCAATGGAC-3', anti-sense primer: 5'-GGCTCAGAAGCACACAAACA-3', product: $297 \mathrm{bp}$; $\beta$-actin sense primer: 5'-GCTCGTCGTCGACAACGGCTC-3', anti-sense primer: 5'-CAAACATGATCTGGGTCATCT TCTC-3', product: 353 bp. PCR conditions were as follows: $95^{\circ} \mathrm{C}$ for $35 \mathrm{sec}, 56^{\circ} \mathrm{C}$ for $35 \mathrm{sec}, 72^{\circ} \mathrm{C}$ for $35 \mathrm{sec} ; 28$ cycles and $72^{\circ} \mathrm{C}$ for $10 \mathrm{~min}$. PCR product $(5 \mu \mathrm{l})$ was loaded for $1 \%$ gel electrophoresis (Kaiji Biotechnology Company, Nanjing, China). $\beta$-actin was used as an internal control. The results were semi-quantified using the UVP gel photograph analyzing system (Bio-Rad) and Quantity One software (Bio-Rad).

Western blot analysis of bcl-2, bax, Cyt-c, caspase-3 and caspase-9. After culturing for $48 \mathrm{~h}$, cells were collected and 

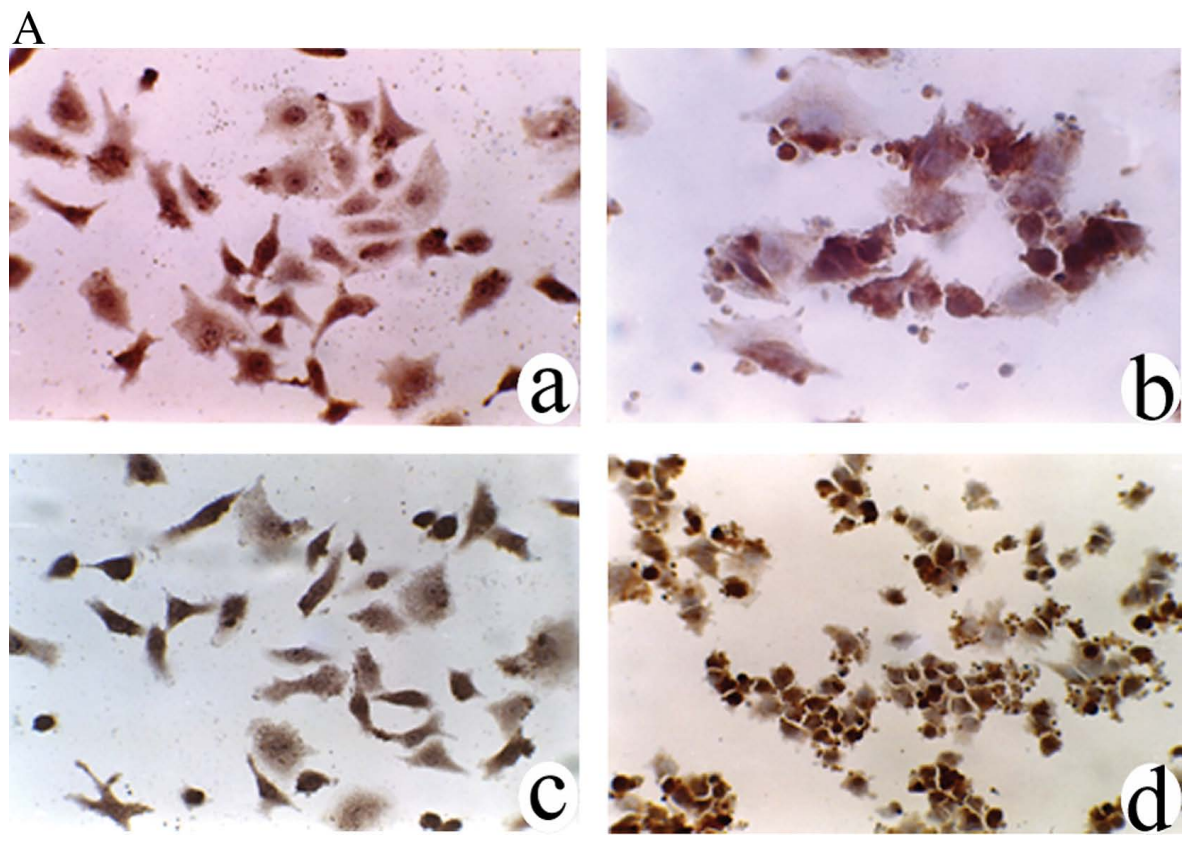

B

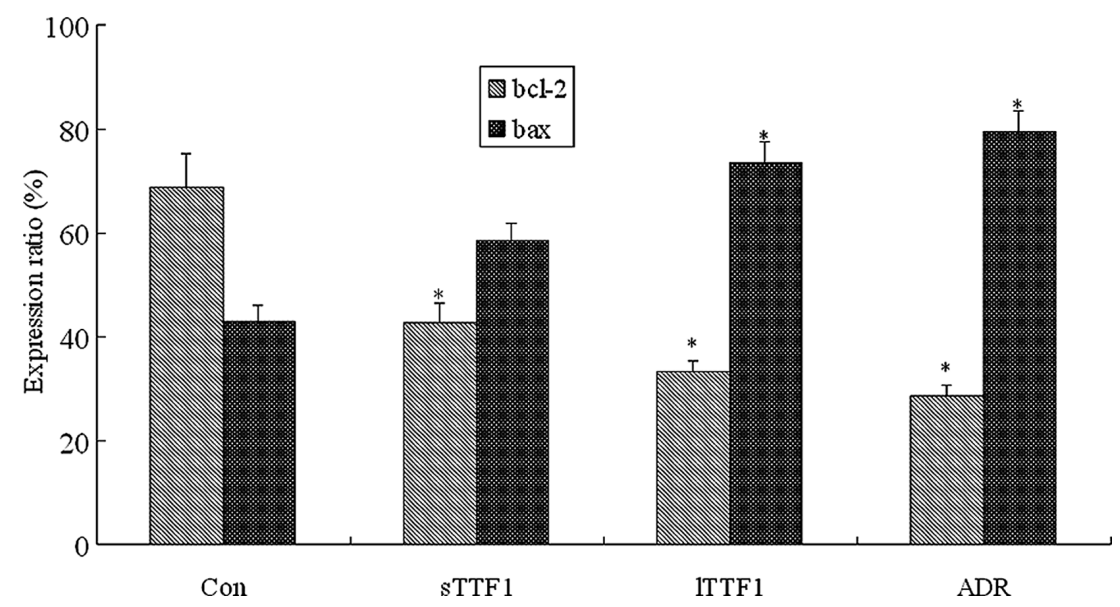

Figure 5. Immunohistochemistry of bcl-2 and bax. (A) Immunohistochemistry of bcl-2 and bax. a and c, staining of bcl-2 and bax in the control group; b and $\mathrm{d}$, staining of bcl-2 and bax in the TTF1 treatment group. (B) Quantification analysis of positive expression rate. " $\mathrm{P}<0.05$ vs Con.

the total proteins were extracted using RIPA lysis buffer. The protein concentration was measured using the BCA method. Protein $(70 \mu \mathrm{g})$ was separated by $10 \%$ SDS-PAGE electrophoresis and then transferred to a PVDF membrane (Pall Corporation, Port Washington, NY, USA). The membrane was blocked with $5 \%$ milk for $1 \mathrm{~h}$ and then incubated at $4^{\circ} \mathrm{C}$ overnight with the primary antibody (mouse anti-human bcl-2, bax, Cyt-c, caspase-3 or caspase-9) at a 1:400 dilution. The membrane was washed four times with TBST and then incubated with the HRP-conjugating secondary antibody at a concentration of 1:5000 for $1 \mathrm{~h}$. After washing four times with TBST, the membrane was developed with BeyoECL Plus. The densitometry of the band was analyzed using a UVP gel photograph analyzing system and the relative expression levels of bcl-2, bax, Cyt-c, caspase-3 and caspase-9 were calculated.

Statistical analysis. Data in all experiments are shown as mean \pm SD. Statistical difference was evaluated using a one-way ANOVA and independent t-test of sample pairs with SPSS 13.0 software.

\section{Results}

Observation of apoptosis using transmission electron microscopy. After treatment with TTF1 (Fig. 1) and ADR (data not shown), cells were shrunken and the cytosol was condensed. The nuclear chromosomes formed a crescent in the nuclear membrane, suggesting partial damage to the membrane and the appearance of nuclear fragment which was condensed and lacking microvilli. There were intact chromosomes, a large nucleolus, a full membrane and many micro-filaments on the cell surface in the control group (Fig. 2).

TTF1-inhibited cell growth of HepG-2. The MTT assay showed that TTF1 inhibited the growth of HepG-2 cells in a time- and dose-dependent manner (Fig. 3). The inhibitive effect 
A
Con
sTTF1
1TTF 1
ADR

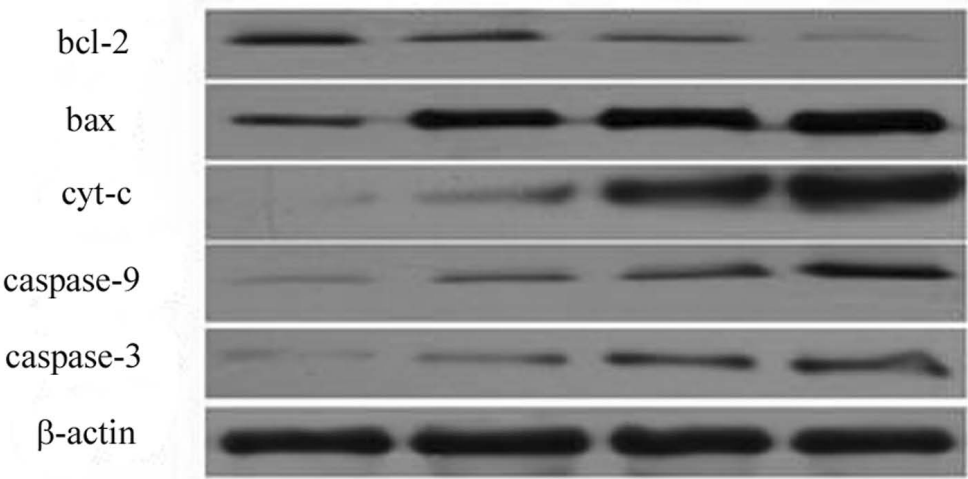

B

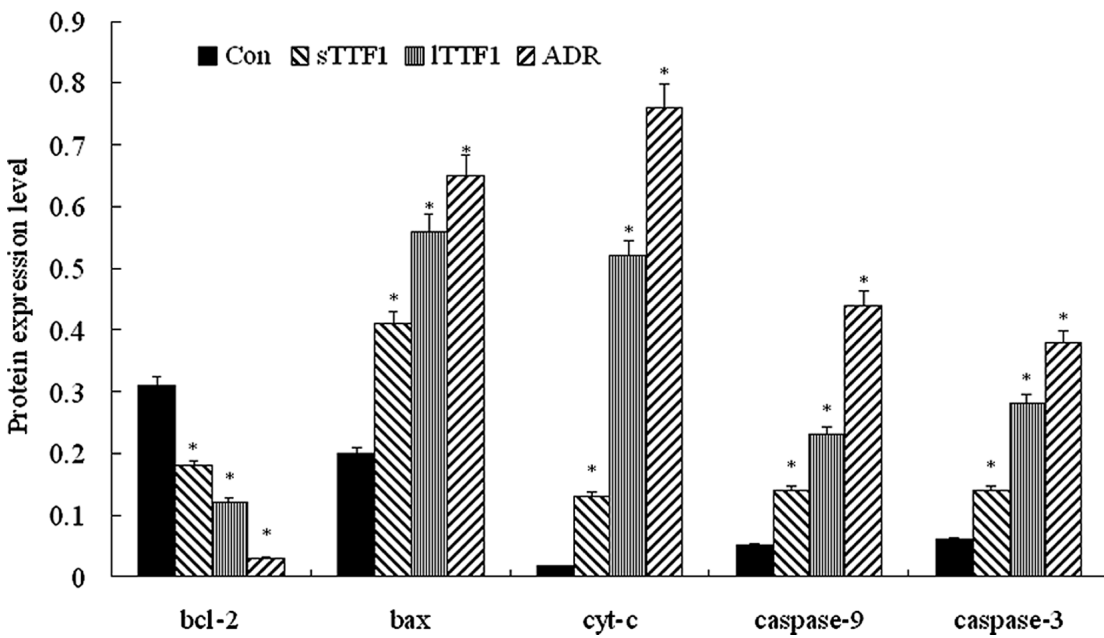

C

सं

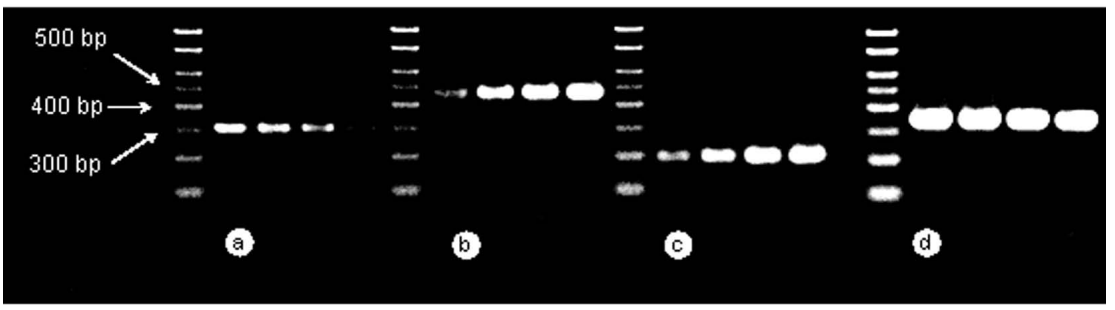

a:bcl-2; b:bax; c:cyt-c; d:ß-actin

D

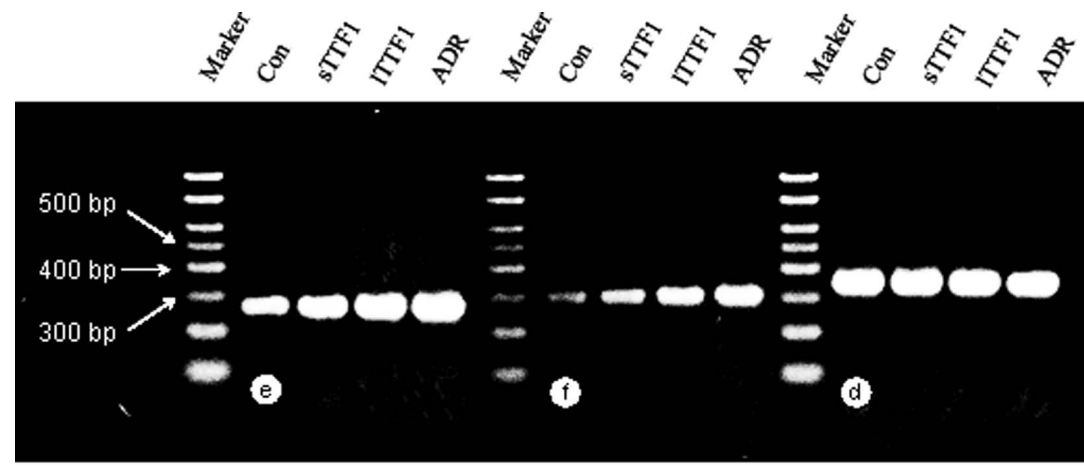

e:caspase-3; f:caspase-9; d: $\beta$-actin

Figure 6. Western blot analysis to determine the protein levels of bcl-2, bax, Cyt-c, caspase-3 and caspase-9. (A) HepG-2 Cells were treated with different concentrations of TTF1 (sTTF1, $50 \mu \mathrm{mol} / 1$; 1TTF1, $100 \mu \mathrm{mol} / 1)$, ADR $(5 \mu \mathrm{mol} / 1)$ and Con (control group cells were treated with normal saline using the same volume as TTF1 treatment) at $48 \mathrm{~h}$. Cells from each group were lysed using RIPA buffer and then were subjected to SDS-PAGE (70 $\mu \mathrm{g} / \mathrm{well})$. Western blot analysis was performed to detect the protein levels of bcl-2, bax, Cyt-c caspase- 3 and caspase- 9 . The intensity of the bcl-2, bax, Cyt-c caspase-3 and caspase- 9 protein bands was determined and normalized with actin's intensity using the UVP imager and is plotted in (B). Quantitative real-time PCR was performed to determine the mRNA expression levels of bcl-2, bax, Cyt-c, caspase-3 and caspase-9 as shown in (C and D). " $\mathrm{P}<0.05$ vs Con. 


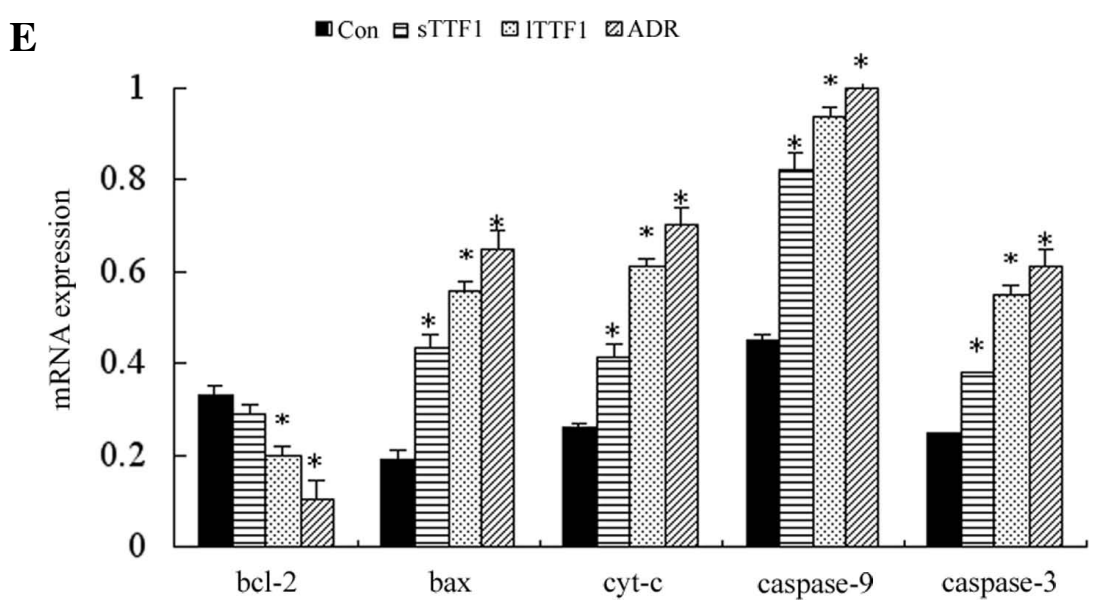

Figure 6. Continued. The intensity of bcl-2, bax, Cyt-c caspase- 3 and caspase- 9 mRNA bands was determined and normalized with actin's intensity by using the UVP imager and plotted in (E). ${ }^{*}<0.05$ vs Con.

of TTF1 was not significantly different from that of ADR in HepG-2 cells $(\mathrm{P}>0.05)$. The $\mathrm{IC}_{50}$ of TTF on HepG-2 cells for 24,48 and $72 \mathrm{~h}$ was $208.7,101.7,96.7 \mu \mathrm{mol} / 1$, respectively.

TTF1-induced apoptosis in HepG-2 cells. FACS analysis showed an apoptotic peak after TTF1 treatment of HepG-2 cells. The apoptotic cell number increased after TTF1 treatment compared to the negative control and was significantly different $(\mathrm{P}<0.05)$ (Fig. 4A and B). ELISA results showed that DNA fragmentation was higher compared to the negative control and was significantly different $(\mathrm{P}<0.05)$ (Fig. 4C). These results together suggest that TTF1 induced apoptosis in HepG-2 cells.

Immunohistochemistry of bcl-2 and bax. Both bcl-2 and bax were located in cytosol and were stained dark-yellow (Fig. 5A). TTF1 treatment induced a decrease in the levels of bcl-2 protein (Fig. 5B) as the number of positive cells decreased (Fig. 5Ab), while the bax protein levels increased as the number of positive cells increased compared to the control.

The effect of TTF1 on transcription and protein expression of bcl-2, bax, Cyt-c, caspase-3 and caspase-9 in HepG-2 cells. RT-PCR and Western blot analysis showed that transcription and protein expression of bcl-2 gradually decreased after TTF1 treatment for $48 \mathrm{~h}$ in HepG-2 cells, while that of bax, Cyt-c, caspase-3 and caspase-9 increased (Fig. 6). This suggests that TTF1 may induce apoptosis of HepG-2 cells through a mitochondrial pathway.

\section{Discussion}

We found that TTF1 inhibited the growth of HepG-2 cells in a time- and dose-dependent manner. The $\mathrm{IC}_{50}$ of TTF1 on HepG-2 cells for 24, 48 and $72 \mathrm{~h}$ was $208.7,101.7,96.7 \mu \mathrm{mol} / \mathrm{l}$, respectively. We chose $0.5 \mathrm{IC}_{50}$ and $\mathrm{IC}_{50}$ as the concentrations in our experiments and cells were treated for $48 \mathrm{~h}$ at these levels in the subsequent study.

Apoptosis is programmed cell death, and the mitochondrial pathway is one of the important pathways that induce apoptosis. Functional changes in mitochondria are closely associated with apoptosis. Mitochondrial injury can be mediated by the mitochondrial membrane. The opening of transfer pores on the mitochondrial membrane leads to the release of many substances, including Cyt-c, Smac/DIABLO, Omi/HtrA2 (a pro-apoptosis factor), and nucleic acid endonuclease $\mathrm{G}$. Among all these components, Cyt-c is thought to be the key factor in apoptosis (11-13). The release of Cyt-c is regulated through non-specific damage to the mitochondrial outer membrane and the formation of transfer channels for Cyt-c. The Bcl-2 family also plays an important role in the release of Cyt-c; its main effect is the inhibition of Cyt-c release through the formation of dimers between the $\mathrm{BH} 3$ domain of bcl-2 and other anti-apoptosis proteins. Bax is a pro-apoptosis protein and is transferred to the mitochondrial membrane to destroy mitochondrial function and release $\mathrm{Cyt}-\mathrm{c}$. Then, the apoptosome complex is formed by the binding of Cyt-c, Apaf-1, Pro-caspase- 9 and dATP. The dimer complex activates caspase- 9 and further activates caspase-3 (3,14-16).

FACS analysis showed that TTF1 induced apoptosis in HepG-2 cells and that the apoptotic cell number increased as the dose increased. RT-PCR and Western blot analysis showed that the transcription and protein expression of bcl-2 was inhibited, while that of bax, Cyt-c, caspase- 3 and caspase- 9 increased. Therefore, we propose that TTF1 may destroy mitochondrial integrity and induce the release of Cyt-c. The activation of caspase- 9 and further activation of caspase- 3 may then induce the degradation of chromosomal DNA and apoptosis in HepG-2 cells.

Sorbaria sorbifolia is rosaceous, perennial herbaceous plant. It has anti-tumor effects but does not damage normal cells and is able to increase immunity, so it is a promising source of plant-based medicines (7). Further study using molecular techniques will focus on the mechanism by which TTF1 induces apoptosis. The relationship between TTF1's physical structure and its effect should be studied, and further structural modification may help us find a new apoptosis inducer with improved curative effect.

\section{Acknowledgements}

We thank the National Natural Science Foundation for the grant (no. 30860374) funding this project. 


\section{References}

1. Popovic S, Baskic D, Djurdjevic P, Zelen I, Mitrovic M Nikolic I, Avramovic D, Radenkovic M and Arsenijevic N: Endoplasmic reticulum stress associated with caspases-4 and -2 mediates korbazol-induced b-chronic lymphocytic leukemia cell apoptosis. J BUON 15: 783-790, 2010.

2. Lu M and Gong X: Upstream reactive oxidative species (ROS signals in exogenous oxidative stress-induced mitochondrial dysfunction. Cell Biol Int 33: 658-664, 2009.

3. Benard G, Faustin B, Galinier A, Rocher C, Bellance N Smolkova K, Casteilla L, Rossignol R and Letellier T: Functional dynamic compartmentalization of respiratory chain intermediate substrates: implications for the control of energy production and mitochondrial diseases. Int J Biochem Cell Biol 40: 1543-1554 2008.

4. Wang P, Xu CS, Xu J, Wang X and Leung AW: Hypocrellin B enhances ultrasound-induced cell death of nasopharyngeal carcinoma cells. Ultrasound Med Biol 36: 336-342, 2010.

5. Nigam N, Bhui K, Prasad S, George J and Shukla Y: [6]-gingerol induces reactive oxygen species regulated mitochondrial cell death pathway in human epidermoid carcinoma A431 cells. Chem Biol Interact 181: 77-84, 2009.

6. Gao LW, Zhang J, Yang WH, Wang B and Wang JW: Glaucocalyxin a induces apoptosis in human leukemia HL-60 cells through mitochondria-mediated death pathway. Toxicol In Vitro 25: 51-63, 2011.

7. Zhang XW, Cui CX and Chen LY: Inhibition of Sorbaria sorbifolia on proliferarion of hepatoma HepG-2 cell line. Zhong Yao Cai 30: 681-684, 2007. (In Chinese).

8. Zhang X, Zhang Y, Guan L, Quan Y and Sun Q: Study on extraction and isolation of active constituents from sorbaria sorbifolia and antitumor effect of the constituents in vivo. Zhong Yao Cai 27: 36-38, 2004. (In Chinese).
9. Zhang X, Zhang X and Quan J: Inhibitory effects of sorbaria sorbifolia on den-induced precancerous hepatic foci and its antioxidative activities in rats. China J Cancer Prev Treat 10: 1137-1140, 2003.

10. Zhang X, Sun Q and Jin M: Effects of Sorbaria sorbifolia extract on anti-oxidative activities in rats with precancerous induced by diethylnitrosamine. J Chin Integr Med 1: 47-50, 2003.

11. Wang Q, Zhao XF, Ji YL, Wang H, Liu P, Zhang C, Zhang Y and $\mathrm{Xu}$ DX: Mitochondrial signaling pathway is also involved in bisphenol a induced germ cell apoptosis in testes. Toxicol Lett 199: 129-135, 2010.

12. Pourahmad J, Hosseini MJ, Eskandari MR, Shekarabi SM and Daraei B: Mitochondrial/lysosomal toxic cross-talk plays a key role in cisplatin nephrotoxicity. Xenobiotica 40: 763-771, 2010.

13. Jiang S, Cai J, Wallace DC and Jones DP: Cytochrome c-mediated apoptosis in cells lacking mitochondrial DNA. Signaling pathway involving release and caspase 3 activation is conserved. J Biol Chem 274: 29905-29911, 1999.

14. You BR and Park WH: Suberoyl bishydroxamic acid inhibits the growth of a549 lung cancer cells via caspase-dependent apoptosis. Mol Cell Biochem 344: 203-210, 2010.

15. Marfe G, Morgante E, Di Stefano C, Di Renzo L, De Martino L, Iovane G, Russo MA and Sinibaldi-Salimei P: Sorbitol-induced apoptosis of human leukemia is mediated by caspase activation and cytochrome c release. Arch Toxicol 82: 371-377, 2008.

16. Yu K, He Y, Yeung LW, Lam PK, Wu RS and Zhou B: De-71induced apoptosis involving intracellular calcium and the bax-mitochondria-caspase protease pathway in human neuroblastoma cells in vitro. Toxicol Sci 104: 341-351, 2008. 